\title{
ACORDO NUCLEAR ENTRE IRÃ E GRUPO 5+1: UMA ANÁLISE SOB A PERSPECTIVA DA INTERDEPENDÊNCIA COMPLEXA
}

\author{
THE NUCLEAR AGREEMENT BETWEEN IRAN AND GROUP 5 + 1: AN ANALYSIS FROM THE \\ PERSPECTIVE OF COMPLEX INTERDEPENDENCE
}

\author{
Leandro Dalalibera Fonseca \\ Mestre em Ciência Política pela Universidade Federal do \\ Paraná,leandrodfonseca@yahoo.com.br
}

\begin{abstract}
Resumo
O presente artigo analisa o acordo histórico firmado entre o Irã e o Ocidente e que tem como interlocutor a AIEA (Agência Internacional de Energia Atômica), sob a perspectiva da visão liberal das relações internacionais, notadamente do Institucionalismo Neoliberal. Para desenvolver essa análise, o artigo examinou os relatórios da Agência no caso específico do Irã, após a assinatura do acordo. A teoria do Institucionalismo Neoliberal sustenta as possibilidades de cooperação entre os Estados e considera os regimes e as organizações internacionais como instrumentos que viabilizam essa mesma cooperação, por meio da aplicabilidade de suas normas. Já a análise dos relatórios busca aferir a efetividade da fiscalização da Agência no acordo em questão. O objetivo desse artigo é compreender o acordo nuclear entre o Irã e o Grupo 5 + 1. Os principais resultados alcançados foram que, partindo de uma visão própria do institucionalismo neoliberal, pode-se compreender o acordo Irã/Ocidente como uma vitória da diplomacia e do papel das organizações internacionais na cooperação entre os Estados.
\end{abstract}

Palavras-chave: Irã; Acordo Nuclear; AIEA; relatórios.

\begin{abstract}
This article analyzes the historical agreement reached between Iran and the West, which has as its interlocutor the IAEA (International Atomic Energy Agency) from the perspective of the liberal vision of international relations, notably of Neoliberal Institutionalism. In order to develop this analysis, the article examined the Agency's reports in the specific case of Iran following the signature of the agreement. The theory of Neoliberal Institutionalism supports the possibilities of cooperation between the States and considers the regimes and the international organizations as instruments that make possible this same cooperation, through the applicability of its norms. The analysis of therefore seeks to assess the effectiveness of the Agency's supervision in the agreement in question. The aim of this article is to understand the nuclear agreement between Iran and the $5+1$ Group. The main results were that, starting from a vision of neoliberal institutionalism, the Iran / West agreement can be understood as a victory for diplomacy and the role of international organizations in cooperation between States.
\end{abstract}

Keywords: Iran; Nuclear Agreement; IAEA; reports. 


\section{INTRODUÇÃO}

Segundo Tourinho (2015), em 20 de julho de 2015, o Conselho de Segurança das Nações Unidas aprovou, por unanimidade, uma resolução que pôs fim a uma década de confronto entre o sistema internacional de segurança coletiva e o Irã sobre o seu programa nuclear. A resolução 2231 (2015) é resultado de um processo negociador de dois anos que culminou na assinatura, em Viena, de um Plano de Ação Integral Conjunto (Joint Comprehensive Plan of Action, ou JCPOA) entre o Irã e o chamado E3+3 (ou P $5+1$ ), um grupo composto por China, Estados Unidos, França, Reino Unido, Rússia e Alemanha especificamente para esse propósito.

O acordo histórico, firmado entre o Irã e o Ocidente, tem como interlocutor a AIEA (Agência Internacional de Energia Atômica) e põe fim a mais de uma década de impasse sobre o programa nuclear iraniano. O objetivo deste artigo é analisar o referido acordo sob a perspectiva do institucionalismo neoliberal. Segundo essa perspectiva é possivel verificar que a cooperação entre os Estados e as organizações internacionais serviria como instrumento para viabilizar essa mesma cooperação por meio da aplicabilidade de suas normas, pelos esforços de fiscalização e acompanhamento do cumprimento dessas normas. Além disso, essa cooperação oferece um espaço de diálogo no qual as negociações entre os Estados tornam-se possíveis, para além das possibilidades de atuação das diplomacias nacionais.

A metodologia adotada para o presente estudo foi a revisão integrativa da literatura, um método que tem a finalidade de reunir e sintetizar resultados de pesquisas sobre um delimitado tema ou questão, de maneira sistemática e ordenada. Esse método contribui para o aprofundamento do conhecimento do tema investigado, permitindo, também, a síntese de múltiplos estudos publicados. Assim, o método possibilita conclusões gerais a respeito de uma particular área de estudo.

O artigo está organizado em cinco seções, além da introdução e das considerações finais. A primeira seção aborda, em linhas gerais, o institucionalismo neoliberal, percorrendo antes a teoria da interdependência complexa, que fornece elementos para a análise dos regimes internacionais, como o TNP (Tratado de Não-Proliferação Nuclear). A segunda seção apresenta um breve histórico sobre a AIEA e o Programa Nuclear Iraniano. Na terceira seção, apresenta-se uma descrição do recente acordo Irã Potências Ocidentais. Na quarta seção, o artigo analisa o acordo com base na teoria institucionalista, e a quinta seção dedica-se à análise dos relatórios da AIEA para o contexto iraniano, como forma de explorar a aplicação do institucionalismo liberal nesse contexto.

\section{A TEORIA DO INSTITUCIONALISMO NEOLIBERAL}

Antes de abordar a teoria institucionalista neoliberal, cabe estabelecer alguns elementos do contexto histórico e teórico das relações internacionais que contribuem para avaliar o papel dos regimes e das organizações internacionais. Nesse contexto, um grau mais elevado de relações transnacionais e intergovernamentais entre os Estados proporciona uma interdependência maior. Os autores afirmam 
que um processo de modernização das economias dos países do sistema internacional acaba por intensificar esta interdependência entre eles. Essa abordagem é particularmente importante quando se observa a importância crescente dos regimes e organizações internacionais a partir do final da Segunda Guerra Mundial, mesmo que os autores realistas, como Hans Morgenthau e Kenneth Waltz (2002), sejam céticos com relação ao papel desses regimes na política internacional. Em áreas mais sensíveis da agenda internacional, é possível identificar a atuação de regimes e organizações internacionais, como é o caso do Tratado de Não Proliferação Nuclear e das Nações Unidas. Para Keohane e Nye (2001), a maior interdependência entre os países torna necessário o funcionamento de regimes e de organizações internacionais. Esse funcionamento é favorecido pelas transformações econômicas experimentadas pelo mundo após a Segunda Guerra Mundial.

Ao longo dos tempos, as nações sempre buscaram a obtenção do poder por meio da força militar e da expansão territorial. Atualmente, contudo, o crescimento da economia interna e o comércio exterior são os meios mais adequados para se obter influência e desenvolvimento econômico (soft power), uma vez que aumentaram os gastos com o uso da força (hard power) e diminuíram os seus benefícios. Quando um país investe em soft power, ele está investindo na sua influência econômica e cultural no mundo, ampliando sua inserção diplomática em foros multilaterais e por meio de relações comerciais, políticas e culturais complexas. Ao contrário, quando uma nação investe em seu hard power, ela está investindo no seu poderio bélico, ou seja, em sua força militar. Na atualidade, o soft power tem se mostrado mais eficiente que o hard power nas complexas relações entre os Estados na política internacional.

Para o realismo, no entanto, as variáveis militares e de segurança permanecem fundamentais na análise das relações internacionais. Essa teoria enxerga a dinâmica das relações internacionais sob a ótica do uso da força e dos conflitos militares entre Estados, enquanto a interdependência complexa reconhece a importância dos chamados atores não-estatais, como empresas multinacionais e organizações não-governamentais. Para os teóricos da interdependência complexa, o mundo atual é, em si, complexo,em razão das variáveis econômicas e dos desafios presentes na agenda internacional.

Segundo uma visão institucionalista neoliberal, os Estados, atualmente, não são mais unidades coesas como antes, e a força militar torna-se menos eficiente num mundo de relações econômicas e políticas complexas e progressivamente mais transnacionais. Nesse contexto, as ferramentas econômicas e diplomáticas seriam mais úteis. A segurança militar teve sua importância reduzida e, em seu lugar, ganham espaço questões de bem-estar social como a previdência, a educação e o atendimento à saúde, entre outras. Contudo, Keohane e Nye (2001) enfatizam que o realismo não é irrelevante nem obsoleto.

Não é impossível imaginar um conflito dramático, ou uma mudança revolucionária, em que o uso da ameaça da força militar sobre uma questão econômica ou entre países industriais avançados se torne real. Assim, as premissas realistas ganhariam uma orientação confiável para explicar os eventos da realidade internacional (KEOHANE e NYE, 2001, p. 28). 
Após a publicação de Power and Interdependence, em 1977, Robert Keohane foi um dos principais expoentes do Institucionalismo Neoliberal dos anos 1980. No livro de 1977, os autores não excluíam totalmente o uso da força (argumento realista), pois mesmo entre os países industrializados do Ocidente, um assunto pode se tornar "uma questão de vida e morte" (idem, p. 29), pois o mundo da interdependência continuaria sendo ocupado pelos Estados e as possibilidades de guerra não poderiam ser descartadas. Nesse caso, o Realismo seria a abordagem mais apropriada aos eventos. Os realistas afirmam que qualquer assunto pode se tornar uma questão de vida ou morte em um mundo anárquico. Já os liberais da interdependência responderão que este raciocínio é simplificado e que muitas questões da agenda internacional envolvem elementos práticos importantes, conforme sustentam Keohane e Nye (1998):

\footnotetext{
$\mathrm{Na}$ linguagem comum, a dependência significa um estado de ser determinado ou significativamente afetado por forças externas. Interdependência, definida de forma mais simples, significa dependência mútua. Interdependência na política mundial se refere a situações caracterizadas por efeitos recíprocos entre países ou entre atores em diferentes países. Estes efeitos geralmente resultam das transações internacionais - os fluxos de dinheiro, bens, pessoas e mensagens através das fronteiras internacionais. Essas operações têm aumentado dramaticamente desde a Segunda Guerra Mundial. Nas últimas décadas, revelam uma tendência geral para muitas formas de interconectividade humana através das fronteiras nacionais que tem dobrado a cada dez anos (KEOHANE \& NYE, 1998, p.8-9)1
}

Nos anos 1970, Keohane e Nye contestavam o realismo no que se refere à centralidade do ator estatal. Para eles, a política internacional é formada por um conjunto de atores não-estatais que possuem interesses próprios e capacidade de influenciar a agenda internacional. Os Estados não seriam os únicos atores da política internacional. Contestado por Kenneth Waltz (2002), para quem os Estados continuam sendo fundamentais e são responsáveis por criar as condições nas quais os demais atores buscam realizar seus objetivos e interesses, Robert Keohane, em particular, aceita que os Estados continuem sendo atores fundamentais. Em AfterHegemony (2005), Keohane defende a importância dos regimes internacionais que poderiam funcionar sem a hegemonia dos Estados Unidos. Embora aceite a posição predominante dos Estados na política internacional, Keohane defenderá que os Estados podem realizar seus interesses e objetivos a partir de um cálculo estratégico capaz de demonstrar a possibilidade da cooperação. Ela seria um meio privilegiado para a realização desses interesses e objetivos. Nesse sentido, as instituições internacionais, como os regimes, são fundamentais no cálculo estratégico dos Estados, entendidos como atores racionais e capazes de buscar a realização de preferências por meio de regimes e organizações internacionais.

\footnotetext{
${ }^{1}$ Original eminglês: "In common parlance, dependence means a state of being determined or significantly affected by external forces. Interdependence, most simply defined, means mutual dependence. Interdependence in world politics refers to situations characterized by reciprocal effects among countries or among actors in different countries. These effects often result from international transactions - flows of money, goods, people, and messages across international boundaries. Such transactions have increased dramatically since World War II. Recent decades reveal a general tendency for many forms of human interconectedness across national boundaries to be doubling every ten years" (KEOHANE \& NYE, 1998, p.8-9).
} 
Nesse artigo, sustenta-se a premissa institucionalista, segundo a qual os Estados, sobretudo no campo da segurança internacional, são os principais atores. No entanto, as organizações internacionais, como a AlEA e as Nações Unidas, jogam um papel relevante nos assuntos militares e relacionados à sobrevivência dos Estados. Com base nessa perspectiva, as próximas seções do artigo formarão uma base histórica e analítica para compreender o acordo estabelecido com o Irã.

\section{A AIEA, O PROGRAMA NUCLEAR IRANIANO E O ACORDO: ASPECTOS DESCRITIVOS E HISTÓRICOS}

A AIEA é anterior ao próprio TNP (Tratado de Não-Proliferação Nuclear) e foi estabelecida como uma organização autônoma no seio das Nações Unidas no ano de 1957, sendo que seus objetivos principais são a promoção do uso pacífico da energia nuclear e o desencorajamento dos usos para fins militares de armas atômicas. A AIEA possui sua sede em Viena e conta com 150 Estados-membros, cujos representantes se encontram anualmente para uma Conferência Geral, onde elegem 35 membros para 0 Conselho de Governadores. Esse conselho reúne-se cinco vezes por ano e prepara as decisões que serão ratificadas pela Conferência Geral.

Com o incremento da proliferação nuclear na década de 1990, as tarefas da AIEA passaram a incluir as inspeções e investigações de suspeitas de violações do Tratado de Não-Proliferação Nuclear, o qual se encontra sob mandato das Nações Unidas. Contudo, caso indícios de uso militar em programas que inspeciona sejam encontrados, a agência apenas poderá reportá-los ao Conselho de Segurança das Nações Unidas, que é o órgão que possui a prerrogativa exclusiva de adoção de medidas coercitivas ${ }^{2}$. A Agência se define como um centro de cooperação no campo nuclear e como uma organização que trabalha com seus Estados-membros e com múltiplos parceiros ao redor do mundo para promover tecnologias nucleares pacíficas e seguras.

Umas das fiscalizações mais controversas realizadas pela AIEA diz respeito ao programa nuclear iraniano, que teve início na década de 1950. Segundo Augusto Luna de Moura e Ivan Ferraz Lemke (2011), o programa nuclear iraniano foi iniciado no período de democratização da tecnologia nuclear para fins pacíficos, iniciada em 1953 com o programa "Átomos para a paz". O Irã e o Paquistão foram os primeiros países beneficiados com o programa, que previa a instalação de reatores nucleares pela empresa norte-americana American Machine and Foundry em seus respectivos territórios. A ajuda dos EUA e seu consequente apoio ao programa nuclear iraniano permaneceu até a Revolução Islâmica de 1979, quando o governo do xá Reza Pahlevi, simpático aos Estados Unidos, foi derrubado por líderes religiosos islâmicos, liderados pelo aiatolá Ruhollah Khomeini. Esse aiatolá instituiu a República Islâmica do Irã com o objetivo de blindar o país da influência ocidental e fundamentar as leis nacionais nos ensinamentos contidos no Alcorão e demais escrituras sagradas do Islã. Na época, a empresa alemã Kraftwerk, contratada para construir dois reatores nucleares em solo iraniano, abandonou as obras,

\footnotetext{
${ }^{2}$ Disponível em www.iaea.org.
} 
alegando falta de pagamento por parte do governo iraniano, ainda que a pressão estadunidense tenha sido o fator determinante da retirada (MOURA e LEMKE, 2011).

Em 1995, após um acordo entre o Irã e a Rússia, a construção dos reatores foi reiniciada. Além disso, estabeleceu-se o ano de 2009 como prazo de entrega da usina nuclear Busher I, o que não ocorreu3. Desde então, o programa nuclear iraniano tem sido "bombardeado" por acusações e questionamentos de países ocidentais (sobretudo os EUA, o Reino Unido, a França e a Alemanha), que colocam em xeque as reais intenções do país com o enriquecimento de urânio. Persiste o argumento, usado por esses países, segundo o qual o programa iraniano seria destinado à produção de ogivas nucleares. Por outro lado, o governo iraniano nega essas acusações, ao mesmo tempo em que reafirma o compromisso assumido ao assinar o Tratado de Não-Proliferação Nuclear (TNP), de destinar a energia atômica tão-somente para fins pacíficos.

Para Augusto Luna de Moura e Ivan Ferraz Lemke (2011), é a partir de meados da década de 1990 que a comunidade internacional observa atentamente o projeto nuclear iraniano, temendo que a argumento mencionado acima seja real, isto é, que o programa seja destinado à fabricação de armas nucleares. O Irã, que diz ser favorável a uma zona livre de armas nucleares no Oriente Médio, passou a ser acusado de desenvolver, clandestinamente, um programa nuclear. Deve-se levar em conta que tal afirmação por parte do Irã sempre tomou como referência Israel, pois, apesar de os israelenses não admitirem nem negarem publicamente que possuem armas nucleares, há uma estimativa de que eles possuem uma considerável quantidade de ogivas.

Para Bahgat (2006, p. 2), o Irã procurou adquirir capacidade nuclear logo em 1957, quando assinou um acordo civil de cooperação nuclear com os Estados Unidos. Esse acordo previa a assistência técnica dos Estados Unidos e a "alocação de vários quilos de urânio enriquecido" em território iraniano. 0 autor prossegue afirmando que:

Primeiramente, nos estágios iniciais da construção de seu programa nuclear, o Irã dependia dos Estados Unidos e de outros países ocidentais. No final da década de 1960, o Centro Atômico da Universidade de Teerã e um reator de pesquisa foram estabelecidos. O combustível enriquecido foi fornecido por uma empresa americana chamada AMF.Na década seguinte, o Irã assinou vários acordos com os Estados Unidos (1974) para comprar oito reatores, com a Alemanha (1974) para construir um reator de energia em Bushehr e com a França ( 1977) para construir dois reatores em Darkhovin. Além disso, o Irã comprou uma parcela de dez por cento em uma usina de enriquecimento de urânio construída por uma empresa francesa chamada Tricastin.Em outras palavras, governos e empresas ocidentais trabalharam em estreita colaboração com a monarquia para construir um ambicioso programa nuclear.

Ainda segundo o autor, quatro conclusões podem ser tiradas a partir desta breve revisão do programa nuclear do Irã. Em primeiro lugar, as autoridades iranianas expressam pouca confiança na comunidade internacional. Em que pese toda pressão política de Washington, várias empresas estrangeiras rejeitam retirar-se dos acordos comerciais que assinaram com a autoridade nuclear iraniana.

${ }^{3}$ Disponivel em http://siem.ufsc.br/files/2011/03/CAPAGUIA_merged_final.pdf\#page=28. 
As autoridades iranianas sempre recordam que as potências estrangeiras não fizeram nada quando o Irã foi atacado por armas químicas e mísseis do Iraque, durante a guerra entre os dois países. Essa experiência ensinou os iranianos que não devem esperar a ajuda de outros países e, portanto, devem desenvolver tecnologia militar própria, com capacidades convencionais e não-convencionais.

O programa nuclear iraniano foi alvo, portanto, de anos de controvérsia, com a aplicação de sanções ao regime dos aiatolás e até ameaça de intervenção militar por parte de Israel e dos países ocidentais. Ao fim desse processo, chegou-se a um acordo histórico acerca do controverso programa. "Acabo de assinar o mapa do caminho entre a República Islâmica do Irã e AIEA para o esclarecimento das questões em suspenso do passado e do presente relativas ao programa nuclear iraniano", declarou YukiyaAmano (diretor-geral da AIEA) à imprensa, antes de celebrar o "avanço significativo" que o acordo representa. "Confio em nossa capacidade de cumprir com este importante trabalho", afirmou o diretor em um comunicado publicado na sede do organismo da ONU, em Viena ${ }^{4}$.

O objetivo do acordo é assegurar que o programa nuclear iraniano tenha um caráter não militar, em troca da retirada das sanções internacionais que asfixiam a economia do país. O texto, que autoriza Teerã a prosseguir com o programa nuclear civil, abre o caminho para uma normalização da presença do Irã no cenário internacional. O acordo possui, como objetivos, garantir que o programa nuclear tenha fins pacíficos, bem como impedir que o Irã se mostre capaz de desenvolver bombas atômicas. O documento final entre Teerã e as grandes potências, de cerca de 100 páginas, prevê a eliminação de todas as sanções internacionais contra o Irã, que também sairá da lista de países sancionados pela ONU.

Para Tourinho (2015), o documento estabelece parâmetros detalhados para o controle externo do programa nuclear iraniano em troca da normalização das relações comerciais e diplomáticas do país. A sua implementação ainda não está garantida; há significativa oposição doméstica nos Estados Unidos e no Irã. Ainda assim, por conta da complexidade e significância do tema, além do histórico de profundo conflito entre as partes, o acordo já se encontra entre os grandes feitos diplomáticos deste século. Parte central do debate sobre o que levou ao sucesso dessas negociações, após anos de impasse, recai sobre o papel das sanções internacionais impostas ao Irã na última década.

Segundo o Ministério das Relações Exteriores russo, o Irã será autorizado a conduzir pesquisa e desenvolvimento com urânio para centrífugas avançadas durante os primeiros 10 anos do acordo, de uma maneira que não acumule urânio enriquecido. Caso alguma parte do acordo não seja cumprida pelos iranianos, as sanções voltarão a entrar em vigor. A aplicação das medidas do pacto será dividida em três etapas: uma preliminar, uma operacional e outra executiva. Com isso, segundo a agência estatal iraniana IRNA, "bilhões de dólares em ativos iranianos congelados serão liberados, as proibições referentes à aviação do país serão canceladas após três décadas", assim como as restrições contra o Banco Central iraniano, o Exército do país e outras empresas estatais.

4 Disponivel em: http://g1.globo.com/mundo/noticia/2015/07/ira-autoriza-investigacao-sobre-o-passado-de-seuprograma-nuclear.html. Acessoem: 06/02/2017. 
O acordo é reconhecido como um avanço importante na tentativa de evitar um conflito no Oriente Médio, que poderia envolver armas nucleares e colocar em risco dois países, em especial, entre outros, Israel e Irã. Na próxima seção, o artigo analisa o acordo, recorrendo ao institucionalismo neoliberal.

Tourinho (2015) considera que o Acordo de Viena não foi resultado simplesmente de uma "capitulação econômica" do Irã por conta das duras sanções. O texto final do acordo revela concessões mútuas entre as duas partes que, de fato, sintetiza as demandas estabelecidas pelas partes no início do processo negociador, há dois anos. Ele foi possível não só porque o Irã decidiu negociar seriamente o seu programa nuclear, mas também porque o espaço para diálogo e barganha nos Estados Unidos foi ampliado durante os últimos anos. Ainda segundo o autor:

Ainda que as sanções não tenham, sozinhas, levado o Irã à mesa de negociações, elas foram parte central das negociações em torno do programa nuclear. Quando houve a transição de poder e o novo governo não atribuiu a mesma importância ao programa nuclear, a retirada das sanções se tornou tema urgente na pauta do governo, já que isso contribuiria, na visão da nova liderança, para a recuperação econômica e a ascensão política do país. Uma vez que os esforços diplomáticos se iniciaram, as sanções se tornaram a principal peça de barganha dos negociadores do $E_{3}+3$, usadas eficazmente em troca de um sistema robusto de verificação do programa nuclear. (TOURINHO, 2015)

\section{ANÁLISE DO ACORDO À LUZ DO INSTITUCIONALISMO NEOLIBERAL}

Para Pereira Macedo (2014), um aspecto da questão nuclear iraniana que a tradição realista não consegue explicar é a influência que grupos internos tiveram na atuação dos diversos Estados no plano internacional. O Estado, enquanto ator central das relações internacionais, é uma caixa-preta que não permite ser influenciado por processos internos ou motivações políticas. Entretanto, parte da razão pela qual o Irã rejeitou o acordo de 2009, depois de tê-lo aceito inicialmente, foi a pressão política interna. Nogueira e Messari (2005, p. 24-25). Semelhantemente, a Declaração de Teerã foi rechaçada pelos EUA. Assim, uma abordagem realista para interpretar o acordo pode sugerir que ele seria inviável, considerando a direito iraniano como Estado soberano à autodeterminação: decidir com independência sobre o seu próprio programa nuclear, sem ingerência externa. Por outro lado, as grandes potências, pertencentes ao Grupo 5+1, utilizaram seu poder dissuasório para evitar a expansão do programa nuclear iraniano, visto por eles como uma ameaça à segurança do Oriente Médio e de todo o planeta. Como afirmam Sebenius e Sink (2013, p. 61):

As percepções dos EUA e do Irã sobre suas opções sem ofertas, além de enumerar possíveis negócios e os interesses de cada lado, exige uma avaliação da percepção de cada lado sobre o que aconteceria se nenhum acordo fosse alcançado (sua "opção sem negociação"). Em relação a uma avaliação de interesse, as opções percebidas de nãoacordo dos Estados Unidos e do Irã são mais difíceis de julgar, pois exigem algumas especulações sobre como cada lado avalia o que realmente ocorreria na ausência de um acordo negociado. A opção sem negociação dos Estados Unidos - ou seja, o caminho da política se um acordo negociado com o Irã não conseguiu ser alcançado - tem sido uma 
questão de controvérsia significativa entre analistas e formuladores de políticas. Ausente um acordo que limite ou elimine o programa nuclear do Irã e sem uma mudança na atual abordagem dos EUA, o provável resultado ao longo do tempo parece ser pelo menos uma capacidade de armas nucleares iranianas ${ }^{5}$

Como parte do acordo, em janeiro de 2016, EUA e União Europeia levantaram as referidas sanções ao Irã. Com o fim das sanções, os iranianos passaram a ter acesso a bilhões de dólares que estavam congelados em bancos do exterior (PEREIRA MACEDO, 2014). O Irã já exerce influência crescente no Iraque e na Síria, onde combate o Estado Islâmico e os rebeldes que se opõem a Bashar al Assad. Naquele momento, os apoiadores de Obama lembram que o presidente fez o que prometeu: investiu na diplomacia e costurou um acordo com a comunidade internacional, já que os Estados Unidos não queriam entrar em mais uma guerra.

O efeito econômico do fim das sanções foi brutal: as bolsas do Golfo Pérsico fecharam praticamente estáveis, mas, em dado momento, chegaram a perder US $\$ 38$ bilhões. O preço do petróleo tipo brent caiu para pouco mais de US\$28 por barril. O problema do excesso de oferta e a intenção do Irã de aumentar a produção contribuíram para a deterioração daquele cenário (PEREIRA MACEDO, 2014). Essas variações nas bolsas e nos valores do petróleo revelam como os acontecimentos localizados em um país têm reflexos na realidade dos demais. Esse raciocínio segue o argumento dos teóricos da interdependência complexa, que enfatizam a dependência mútua entre Estados e outros atores da política internacional, os quais estão sujeitos às dinâmicas econômicas e políticas internacionais.

Esta dependência mútua evidencia a necessidade do acordo celebrado, pois ao mesmo tempo em que o Irã necessitava do acordo para evitar prejuízos à sua economia, o Ocidente também precisava do acordo para evitar a criação de um conflito bélico no Oriente Médio. Um conflito dessas proporções poderia levar a consequências desastrosas para todos os países que dependem da importação do petróleo como fonte de energia. Mesmo que algumas empresas e países sejam favorecidos pela elevação abrupta dos preços do petróleo, como ocorreu nos anos 1970, muitas economias dependentes do petróleo seriam afetadas por uma guerra de grandes proporções no Oriente Médio, sobretudo se envolvesse a possibilidade de recurso a armas nucleares.

O livre-comércio ajuda na construção da paz e no bem-estar da sociedade internacional, na medida em que promove o contato e a tolerância entre diferentes culturas, elementos essenciais para a criação de laços entre Estados. Vista de modo pragmático, a interdependência econômica dos Estados, criada pelo livre-comércio, torna a guerra indesejável e incompatível com os propósitos de uma

\footnotetext{
5Tradução em português. Original em inglês: "U.S. and iranian perceptions of their no-deal options beyond enumerating potential deals and each side's interests, the frame work calls for an assessment of each side's perception of what would happen if no deal were reached (its "no-deal option"). Relative to an interest assessment, the United States' and Iran's perceived no-deal options are more difficult to judge, as they require some speculation about how each side assesses what would actually transpire absent a negotiated agreement. The United States' nodeal option-that is, its policy path should a negotiated agreement with Iran fail to be reached-has been a matter of significant controversy among analysts and policymakers. Absent an agreement limiting or eliminating Iran's nuclear program and without a change in the current U.S. approach, the likely outcome over time appears to be at least an Iranian nuclear weapons capability" (SEBENIUS e SINK, 2013, p. 61).
} 
sociedade (NOGUEIRA E MESSARI, 2005, p. 62). Esse conceito do liberalismo contribui para explicar porque as grandes potências Ocidentais consentiram em levantar as sanções econômicas e comerciais impostas ao país persa.

Para Roberto (2015), "em relação à geopolítica eurasiana, a normalização do Irã no cenário internacional representa uma nova série de oportunidades políticas e econômicas, principalmente devido às enormes reservas de petróleo e gás natural, além de uma população de 70 milhões de habitantes, em geral de classe média". Ainda segundo Bhadrakumar (2015, p.6):

[...] é possível que um dos primeiros passos do governo iraniano também seja uma política de 'olhar para o leste', que poderia se concretizar, em um primeiro passo, através do oleoduto entre o Irã e o Paquistão, já planejado, porém interrompido devido às sanções internacionais. O lado iraniano já está completo, restando apenas a construção no território paquistanês. O projeto ligaria o porto terminal no Golfo Pérsico de Asaluyeh, no lado iraniano, ao porto de Gwadar no Paquistão, construído com capital chinês. O oleoduto no lado paquistanês, de apenas $80 \mathrm{~km}$ de extensão e custando 2 bilhões de dólares, poderá ser financiado pela China que, segundo autoridades paquistanesas, teria interesse em conectar esse novo oleoduto ao já existente Corredor Econômico China-Paquistão, um outro duto de $700 \mathrm{~km}$ entre os dois países, fazendo com que Pequim se beneficiasse diretamente do petróleo iraniano.

Para Roberto (2015), percebe-se que há uma inflexão na postura da República Islâmica a partir dos eventos da chamada Primavera Árabe, principalmente com a guerra na Síria. Assim, dois principais fatores podem ser identificados como fundamentais para explicar o fato de Teerã aceitar o acordo nuclear: a deterioração de sua estratégia regional a partir da crise síria e um maior estrangulamento de sua economia por meio de novas sanções. "A partir de 2011, tanto o Irã quanto os EUA se viram prejudicados com a realidade do Oriente Médio e passaram a perceber a necessidade de negociar" (KECK apud ROBERTO, 2015, p. 2).

De fato, por meio de uma análise mais ampla da conjuntura, existe a percepção de que os dois fatores citados acima foram decisivos para a mudança de postura do Irã. Além desses fatores, Tourinho afirma que (2015, p. 45):

[...] foram fatores internos, incluindo a alternância de poder, que levaram o Irã à mudança de postura no processo negociador ao longo dos últimos dois anos. Entretanto, as sanções cumpriram outros papéis importantes ao longo da gestão da crise nuclear, que devem ser enfatizados. Primeiro, as sanções da ONU, seletivas e restritas aos programas nuclear e balístico, foram relativamente eficazes em dificultar o acesso do Irã à tecnologia e material necessário para a realização do seu programa nuclear. Ainda que o programa tenha de fato evoluído nesse período, os custos políticos e econômicos de qualquer avanço nesse setor aumentaram substancialmente por conta das restrições universais impostas pelo Conselho de Segurança.

Ainda segundo o autor, as sanções impostas pela União Europeia desde 2010, de fato, exacerbaram o desarranjo econômico do país, ainda que as decisões políticas do governo Ahmadinejad e o declínio do preço do petróleo também tenham sido fatores proeminentes (Tourinho, 2015). Conforme assevera Keck (2013), 
De fato, a tendência natural das pessoas de se concentrar em personalidades e indivíduos obscurece um aspecto importante da política global. Semelhante à competição na teoria econômica de Adam Smith, a geopolítica é a "mão invisível" que molda as relações internacionais. As relações entre os EUA e o Irã não são exceção. Embora a eleição de Hassan Rouhani como presidente do Irã fosse inegavelmente importante, há forças maiores empurrando os EUA e o Irã para o détente. Desde o final da Guerra Fria, houve três fases distintas nas relações EUA-Irã. Durante o primeiro período, que durou desde o final da Guerra do Golfo até 2005, o poder dos EUA no Oriente Médio estava no auge. Os formuladores de políticas americanos usaram esse poder para construir uma ordem regional liderada pelos EUA que claramente excluía o Irã e o Iraque. Isto começou sob George H. W. Bush com a Conferência de Madri em 1991, e foi codificado sob o governo Clinton com a doutrina da "dupla contenção". Durante este período de tempo, os responsáveis pelas políticas dos EUA viram poucos motivos para se comprometer com o Irã, rejeitando várias propostas de Teerã, incluindo a notória proposta de barganha do Irã em $2003^{6}$.

Ou seja, houve percepção de ambos os lados, no sentido de que a continuidade da escalada de tensões na região poderia trazer graves prejuízos político-econômicos tanto para os EUA como para o Irã. Assim, nesse caso concreto, um acordo acabaria sendo benéfico tanto do ponto de vista político como do ponto de vista econômico.

Felizmente, os dois lados abdicaram de parte de seus interesses imediatos em prol dos seus interesses de longo prazo. Ainda que o governo de Israel tenha criticado abertamente o acordo, seu cumprimento sob o crivo das inspeções da AIEA dá legitimidade ao argumento de Teerã de que seu programa nuclear possui fins pacíficos. Em termos práticos, o acordo demonstra o argumento de Keohane segundo o qual os Estados recorrem às instituições, à cooperação, aos acordos e aos tratados a partir de um cálculo estratégico baseado em seus interesses, sejam eles políticos ou econômicos. 0 acordo demonstra que os dois lados (os países liderados pelos Estados Unidos e o Irã) consideraram vantajoso negociar e condicionar o programa nuclear iraniano ao crivo da AIEA e ao conteúdo do TNP. O acordo, por fim, não beneficiou apenas os países ocidentais liderados pelos Estados Unidos, pois o Irã não tinha mais meios de sustentar seu programa com os pesados custos impostos pelas sanções e pressões internacionais. Nesse sentido, o Irã teve que ceder para evitar arcar com os custos políticos e econômicos mais elevados da manutenção do seu programa nuclear. Tratou-se, então, de um cálculo estratégico que envolveu o recuo iraniano frente aos custos elevados da manutenção de uma posição de enfrentamento às grandes potências.

\section{ANÁLISE DOS RELATÓRIOS AIEA}

Para examinar o papel da AlEA na questão do Irã, esta seção apresenta uma síntese dos documentos disponibilizados pela Agência. Dessa forma, será possível compreender a função da AIEA no exercício de pressão sobre o país a partir da assinatura do acordo. A seguir, é apresentada uma análise dos relatórios da AIEA sobre o programa nuclear iraniano, a qual possui como marco temporal o período

\footnotetext{
${ }^{6}$ Disponível em http://thediplomat.com/2013/11/the-geopolitics-of-a-us-iran-detente/. Acesso em: 06/02/2017.
} 
de 2017 a 2018. Tais relatórios estão disponíveis no site da AIEA (www.iaea.org/newscenter/focus/iaeairan/iaea_reports.shtml).

\subsection{RELATÓRIO AIEA o6 DE JUNHO DE 2017}

Segundo consta no relatório, o informe do Diretor Geral da Junta de Governadores e, paralelamente, ao Conselho de Segurança das Nações Unidas (o Conselho de Segurança), trata sobre o cumprimento pela República Islâmica do Irã de seus compromissos relacionados com a energia nuclear em virtude do Plano de Ação Integral Conjunto (PAIC) e sobre assuntos relacionados com a verificação e vigilância no Irã à luz da resolução 2231 (2015) do Conselho de Segurança. Desta forma, proporciona informação sobre assuntos financeiros e sobre as consultas e intercâmbios de informação do Organismo com a Comissão Conjunta, estabelecida pelo PAIC.

Nos itens 03 e 04 da Seção "Antecedentes", o relatório afirma que, em dezembro de 2016 e em janeiro de 2017, o Diretor General apresentou aos Estados Membros nove documentos, elaborados e referenciados por todos os participantes da Comissão Conjunta, nos que eram oferecidos esclarecimentos para a aplicação das medidas do Irã relacionadas à energia nuclear, em conformidade com o PAIC. O custo estimado para o Organismo para a aplicação do Protocolo Adicional do Irã e da verificação e vigilância do cumprimento dos compromissos do Irã relacionados com a energia nuclear que são expostos no PAIC chega a 9,2 milhões de euros anuais. Para 2017, foi necessário um financiamento extra orçamentário de 6,2 milhões de euros dos 9,2 milhões de euros. Em 24 de maio 2017, havia 7,3 milhões de euros de fundos extra orçamentários disponíveis para cobrir o custo das atividades relacionadas com o PAIC em 2017 e a posteriori.

Já na seção "Atividades de verificação e vigilância no marco do PAIC", o relatório afirma que, desde o dia 16 de janeiro de 2016 (o Dia de Aplicação do PAIC), o Organismo verificou e vigiou o cumprimento pelo Irã dos seus compromissos relacionados com a energia nuclear tendo em vista os arranjos estabelecidos no PAIC5 e "em consonância com as práticas habituais de salvaguardas do Organismo e de modo imparcial e objetivo".

No item "Atividades relacionadas com a água pesada e o reprocessamento" o Irã não seguiu construindo o reator de pesquisa de água pesada de Arak (reator IR-40) sobre a base de seu projeto original. O Irã tampouco produziu pastilhas de urânio natural, agulhas de combustível e conjuntos combustíveis projetados especificamente para o reator IR-40 em seu projeto original. Além disso, todas as pastilhas de urânio natural e os conjuntos combustíveis existentes seguiram armazenados sob a vigilância permanente do Organismo.

O Irã seguiu informando ao Organismo sobre a existência de água pesada tanto no país quanto na planta de produção HWPP. Em uma carta datada de 23 de abril de 2017, o Irã informou ao Organismo que havia previsto parar a planta no dia 27 de abril de 2017 para realizar a manutenção programada. No 
dia 16 de maio de 2017, o Organismo verificou que a planta estava paralisada e que havia 128,2 toneladas métricas de água pesada. No período compreendido pelo relatório, o Irã não teve mais de 130 toneladas métricas de água pesada.

No item "medidas de transparência", o relatório afirmou que o Irã seguiu permitindo que a AIEA implementasse, mediante acordos previamente combinados com o próprio país, medidas de contenção e de vigilância. O Irã também facilitou ao Organismo toda a informação necessária para que este pudesse verificar tanto a produção de concentrado de mineral de urânio quanto a existência deste produzidas no Irã ou obtidas de qualquer outra fonte.

O relatório afirmou ainda que a AIEA daria continuidade em seus esforços para que os materiais nucleares declarados não fossem desviados das instalações nucleares, que haviam sido declaradas pelo Irã no contexto do Acordo de Salvaguardas. Além disso, a organização deu continuidade nas avaliações para identificar materiais e atividades nucleares que não foram declarados pelo Irã. O documento afirma ainda, que desde o dia de sua aplicação, a Agência esteve verificando o cumprimento pelo Irã de seus compromissos relacionados com a energia nuclear em virtude do PAIC.

\subsection{RELATÓRIO AIEA O4 DE SETEMBRO DE 2017}

No relatório de setembro de 2017, na seção C.3. "Pesquisa e desenvolvimento, fabricação e inventário com relação às centrífugas", afirma-se que não foi acumulado urânio enriquecido por meio de atividades de pesquisa e desenvolvimento sobre enriquecimento, e as atividades sobre enriquecimento do Irã com e sem urânio foram realizadas por meio da utilização de centrífugas, em conformidade com os limites definidos no PAIC.

De acordo com o relatório, o Irã proporcionou à Organização: declarações de sua produção; seu inventário de tubos de rotor e; de suas centrífugas. Além disso, o país permitiu à AIEA verificar os materiais inventariados. Assim, a organização manteve o monitoramento sobre os materiais nucleares iranianos. Com isso, a AIEA verificou que a equipe declarada utilizou seus recursos em conformidade com as atividades previstas no PAIC. O Irã não fabricou nenhuma centrífuga IR-1 para substituir as avariadas ou inservíveis. Dessa forma, todos os tubos de rotor, foles e conjuntos rotores declarados estiveram submetidos à vigilância permanente da Organização.

Na conclusão, o relatório afirmou que o Irã seguia aplicando, em caráter experimental, o Protocolo Adicional a seu Acordo de Salvaguardas, em conformidade com o artículo 17-b desse Protocolo. Com base no Protocolo Adicional, o organismo continuou avaliando as declarações do Irã em virtude do Protocolo Adicional e realizando visitas de acesso complementar em virtude do Protocolo Adicional a instalações e outros lugares do Irã. A AIEA prossegue com a verificação e vigilância do cumprimento pelo Irã de seus outros compromissos, relacionados com a energia nuclear no marco do 
PAIC. Durante o período do presente relatório, a organização não compareceu a reuniões do Grupo de Trabalho sobre Aquisições da Comissão Conjunta do PAIC.

Por fim, esse relatório aponta que a AIEA seguiu verificando o não desvio dos materiais nucleares declarados nas instalações nucleares, em conformidade com seu Acordo de Salvaguardas. Além disso, a AIEA também deu continuidade às avaliações com relação a materiais e a atividades nucleares não declarados pelo Irã. Afirma ainda, que desde o dia de sua aplicação, a Agência esteve verificando o cumprimento pelo Irã de seus compromissos relacionados com a energia nuclear, de acordo com o PAIC.

\subsection{RELATÓRIO AIEA 14 DE NOVEMBRO DE 2017}

Segundo consta no relatório, no dia 29 de outubro de 2017, o Diretor Geral se reuniu em Teerã com o Presidente do Irã, Sr. Hassan Rouhani, com o Vice-presidente do Irã e Presidente da Organização de Energia Atômica do Irã (AEOI), Sr. Ali AkbarSalehi, e com o Ministro de Relações Exteriores do Irã, Sr. Mohammad Javad Zarif. No curso dessas reuniões, o Diretor Geral insistiu na importância do pleno cumprimento pelo Irã de seus compromissos relacionados com a energia nuclear, no contexto do PAIC. Ainda segundo o relatório, o Irã seguiu aplicando o Protocolo Adicional a seu Acordo de Salvaguardas, em conformidade com o artigo 17 do Protocolo Adicional.

A Organização continuou avaliando as declarações do Irã e realizou visitas de acesso complementar a todas as instalações e lugares do Irã que, segundo o Protocolo Adicional, deveria visitar. A Organização prosseguiu com a verificação e a vigilância do cumprimento pelo Irã de seus outros compromissos relacionados com a energia nuclear, no marco do PAIC. No período compreendido pelo presente relatório, a Organização esteve presente em uma reunião do Grupo de Trabalho sobre Aquisições da Comissão Conjunta.

O relatório afirma que a AIEA continua verificando o não desvio dos materiais nucleares declarados nas instalações nucleares e lugares situados fora das instalações nos que se utilizam habitualmente materiais nucleares declarados pelo Irã, conforme preconiza seu Acordo de Salvaguardas. Seguiram-se realizando com relação ao Irã avaliações relativas à ausência de materiais e atividades nucleares não declaradas. Assim, desde o Dia de Aplicação, a Organização esteve verificando o cumprimento, pelo Irã, de seus compromissos relacionados com a energia nuclear, conforme disposições do PAIC.

\section{DISCUSSÃO DOS RESULTADOS E CONSIDERAÇÕES FINAIS}

Partindo de uma visão própria do institucionalismo neoliberal, pode-se compreender o acordo Irã/Ocidente como uma vitória da diplomacia e do papel das organizações internacionais na cooperação entre os Estados. O liberalismo da interdependência baseia-se na visão da dependência mútua, ou seja, 
de que os indivíduos, e mesmo os governos, sofrem o impacto do que acontece em todos os lugares do mundo. Nessa corrente teórica, destacam-se autores como Keohane e Nye, os quais se opõem ao conceito realista de "poder" e defendem o conceito de "interdependência complexa", que consistiria justamente na existência de múltiplos canais de ligação entre sociedades. Esses canais compreendem desde interações informais entre autoridades e entre atores privados até relações interestatais formais (CASTRO, 2005, p. 24). Dessa forma, esses autores valorizam as organizações internacionais como atores importantes para o processo de cooperação entre os Estados.

As relações internacionais tornam-se, assim, mais semelhantes à política nacional: "Questões diferentes geram coalizões diferentes, ambas dentro de governos e entre governos, e envolvem diversos graus de conflito. De fato, segundo Keohane e Nye (2001, p. 25), "a política transcende fronteiras". Na maioria desses conflitos entre os Estados, a força militar é irrelevante. Portanto, recursos de poder além das armas, como habilidade de negociação, passam a ter suma importância. Por fim, sob a interdependência complexa, os Estados preocupam-se mais com a "política inferior" do bem-estar e menos com a "política superior" da segurança nacional (KEOHANE e NYE 2001, p. 24-6).

Com base nos dados obtidos pelos relatórios analisados, conclui-se que tanto o Acordo denominado PAIC quanto a AIEA têm obtido êxito em evitar que o Programa Nuclear Iraniano seja desviado para fins militares. Da análise dos relatórios infere-se que, por hora, as medidas de fiscalização da Agência sobre o Programa Nuclear iraniano têm sido efetivas, pois reportam a colaboração do Irã com a AIEA no sentido de aplicar com efetividade os termos acordados no PAIC. Para Young (2000), a efetividade das instituições internacionais varia diretamente com o nível de interdependência dos participantes.

Há interdependência quando as ações dos membros individuais de um sistema social influenciam, objetiva ou subjetivamente, o bem-estar de outros membros do sistema. Os sujeitos interdependentes são afetados mutuamente pelo seu comportamento, reagindo uns aos outros de forma sensível; quanto maior a interdependência, mais pronunciados esses efeitos e reações. Observa-se pela análise do PAIC e dos relatórios, que a interdependência entre o Irã e os demais Estados subscritores do acordo tem contribuído para que o país persa efetivamente cumpra com os termos acordados no PAIC.

Assim, é também pertinente enfatizar que este trabalho não nutriu, em nenhum momento, a ambição de esgotar o assunto, mas sim de lançar uma nova luz sobre o tema, de forma a analisar a postura da AIEA e das grandes potências nucleares frente ao programa nuclear iraniano. É importante salientar, também, que, com a ascensão de Donald Trump à presidência dos Estados Unidos, há uma grande tendência a haver mudanças em relação à política dirigida ao acordo nuclear iraniano. $O$ Departamento do Tesouro dos Estados Unidos anunciou, em 2017, um novo pacote de sanções contra o Irã, por conta do recente teste de míssil realizado pelo país persa. Os alvos das medidas foram treze pessoas e doze empresas e entidades iranianas suspeitas de estarem ligadas com o programa armamentista de Teerã. Em 08 de maio de 2018, Trump anunciou, finalmente, a retirada dos EUA do 
acordo nuclear com o Irã. Esse tema, no entanto, requer um novo artigo e uma nova abordagem, acompanhando os desdobramentos do acordo e as relações recentes das grandes potências com o Irã.

Artigo recebido em o1nov 2018.

Aprovado em 18dez 2018.

\section{REFERÊNCIAS}

AIEA - Agência Internacional de Energia AtômicalInternationalAtomic Energy Agency. Disponível em: http://www.iaea.org/. Acesso em: 18 de dezembro de 2018.

BAHGAT, Gawdat. Nuclear proliferation: The IslamicRepublicof Iran.IranianStudies, vol. 39, n. 3, p. 307$327,2006$.

BHADRAKUMAR, M. K. Iran's 'Look East' policytakeswing. Asia Times Online,17 de julho de 2015. Disponivel em: http://www.atimes.com/irans-look-east-policy-takes-wings/ Acesso em: 18 de dezembro de 2018.

CLAUSEWITZ, Carl Von. Da guerra. São Paulo: Martins Fontes, 1996.

FISCHER, David. Historyof AIEA. Disponível em: http://www.iaea.org. Acesso em: 18 de dezembro de 2018.

FONSECA, Leandro Dalalibera. A AIEA: Agência Internacional de Energia Atômica e a efetividade de suas medidas no cumprimento dos dispositivos do Tratado de Não- Proliferação Nuclear: estudo de caso do programa nuclear iraniano. Dissertação (Mestrado em Ciência Política), Programa de Pós-Graduação em Ciência Política, Universidade Federal do Paraná. Curitiba, 2012.

GOLDSCHMIDT, B. The Negotiationof NPT.IAEA Bulletin, Vol. 22, n. 3/4 p. 73-80, 1980.

GOLDEMBERG, José. O Protocolo Adicional do TNP. Disponível em:https://goo.gl/xD1nUg. Acesso em: 18 de dezembro de 2018.

HERZ, Mônica. Organizações Internacionais: história e práticas. Rio de Janeiro: Elsevier, 2004.

JACKSON, R.; SORENSEN, Georg. Introdução às Relações Internacionais. Rio de Janeiro: Zahar, 2007.

KECK, Zachary. The Geopoliticsof a US-Iran Détente. The Diplomat, 20 de novembro de 2013. Disponivel em: ttps://thediplomat.com/2013/11/the-geopolitics-of-a-us-iran-detente/ Acesso em: 18 de dezembro de 2018.

KEOHANE, Robert O. NYE, Joseph S. Power andlnterdependence in thelnformation Age. ForeignAffairs, vol. 77 n. 5, September/October 1998. 
KEOHANE, Robert O.; NYE, Joseph S. Power andInterdependence. New York: Longman, 2001.

KEOHANE, Robert. AfterHegemony - CooperationandDiscord in the World PoliticalEconomy. Princeton: Princeton University Press, 2005.

NETO, Ibrahim AdbulHak. Armas de Destruição em Massa no Século XXI: Novas Regras para um Velho Jogo - O paradigma da Iniciativa de Segurança contra a Proliferação. Brasília: FUNAG, 2011.

NOGUEIRA, João P. e MESSARI, Nizar. Teoria das relações Internacionais: Correntes e teorias. Rio de Janeiro: Elsevier, 2005.

PEREIRA MACEDO, Maria Clara Guerra Gomes. Declaração de Teerã: a iniciativa turco-brasileira para a questão nuclear iraniana. Brasília: Unb, 2014.

PANELLI CÉSAR, Luis Fernando. TNP (1968). In: MAGNOLI, Demétrio (Org.) História da Paz. São Paulo: Editora Contexto, 2008.

ROBERTO, William Moraes.O acordo nuclear do Irã: uma análise das possíveis razões e impactos. Nerint, 2015 .

ROBINSON, William. Capitalismo Transnacional. Entrevista. Disponível em: https://goo.gl/wpwS8x.Acesso em: 18 de dezembro de 2018.

ROSENAU, James. The Studyof Global Interdependence: EssaysontheTransnationalisationof World Affairs. New York: Nichols, 1980.

SEBENIUS, James K.SINGH, Michael K. Is a Nuclear Dealwith Iran Possible?AnAnalytical Framework for the Iran Nuclear Negotiations. International Security, vol. 37, issue 3, p. 52-91, 2013.

TOURINHO, Marcos. O acordo nuclear com o Irã: O papel e as contribuições das sanções internacionais.Política Externa, São Paulo, 2015. Disponível em: http://politicaexterna.com.br/280g/oacordo-nuclear-com-o-ira-o-papel-e-contribuicoes-das-sancoes-internacionais/ Acesso em: 18 de dezembro de 2018.

UNITED NATIONS. The Security Council: WorkingMethodsHandbook. United NationsPublication, 2012.

WALTZ, Kenneth. Teoria das relações internacionais. Lisboa: Gradiva, 2002. 